\title{
Challenges to Quit Smoking among Smokers in Bandar Baru Salak Tinggi, Sepang, Selangor, Malaysia
}

\author{
Nurulfarahin K.A., Nina S.A., Lailati S., Raisah Z., Izzuddin A., Sabariah A.H. \\ Faculty of Medicine, Cyberjaya University College of Medical Sciences, Malaysia
}

\begin{tabular}{|c|c|}
\hline Article Info & ABSTRACT \\
\hline Article history: & \multirow{12}{*}{$\begin{array}{l}\text { Cigarette smoking is the largest preventable risk factor for morbidity and } \\
\text { mortality in developed countries. The prevalence of smoking is increasing in } \\
\text { Malaysia. Over the years, we have accumulated the knowledge of the risks } \\
\text { and dangers of smoking towards health and had used these as interventions to } \\
\text { motivate smokers to quit smoking. However, quitting smoking is hard as } \\
\text { people who stop smoking often start again because of weight gain, stress and } \\
\text { withdrawal symptoms. Therefore, this study aimed to identify the challenges } \\
\text { to quit smoking among smokers in Bandar Baru Salak Tinggi, Sepang, } \\
\text { Selangor, Malaysia. A cross-sectional study was conducted with a } \\
\text { combination of stratified and simple random sampling. The study was } \\
\text { conducted via a face-to-face interview using a standardized questionnaire. } \\
\text { The data was analyzed using SPSS (Statistical Package for Social Sciences) } \\
\text { Version } 20.0 \text {. Easy availability of cigarettes was the most challenging factor } \\
\text { (86\%) followed by seeing things that reminded the respondents of smoking } \\
\text { (58\%), feeling lost without smoking (53\%) and withdrawal symptoms (47\%). } \\
\text { To combat these challenges, it is imperative to strengthen the enforcement on } \\
\text { regulations advertisement and display of cigarettes and develop more } \\
\text { activities on motivation among smokers and their families, which may be } \\
\text { organized by government or non-government organizations. Other than that, } \\
\text { another important aspect in the promoting smoking cessation program is to } \\
\text { encourage smoke-free homes. }\end{array}$} \\
\hline Received Dec 23, 2017 & \\
\hline Revised Feb 26, 2018 & \\
\hline Accepted Mar 12, 2018 & \\
\hline Keyword: & \\
\hline Challenges & \\
\hline Quit smoking & \\
\hline Refusal factors & \\
\hline Smokers & \\
\hline $\begin{array}{l}\text { SImokers } \\
\text { Smoking }\end{array}$ & \\
\hline Smoking & \\
\hline & \\
\hline
\end{tabular}

Copyright $\odot 2018$ Institute of Advanced Engineering and Science. All rights reserved.

\section{Corresponding Author:}

Sabariah Abd Hamid,

Faculty of Medicine,

Cyberjaya University College of Medical Sciences,

Malaysia.

Email: sabariah@cybermed.edu.my

\section{INTRODUCTION}

A study done in Putrajaya and Pahang in the year 2008 among adolescent reported that the prevalence of smokers are $8.5 \%$ and $17.2 \%$, respectively [1]. The National Health Morbidity Survey 2015, which has been done inclusive of all the states in Malaysia, reported that approximately $22.8 \%$ of the Malaysian population aged 15 years and above were smokers, and out of the current smokers, $20.5 \%$ are daily smokers [2].

World Health Organization has reviewed that more than 6 million of deaths were the result of direct tobacco use while around 890000 were the result of non-smokers being exposed to second-hand smoke [3]. Cigarette smoking is the largest preventable risk factor for morbidity and mortality in developed countries and smoking kills 20,000 Malaysians every year and will increase to 30,000 by the year 2020 if the pattern of smoking does not change [2].

However, quitting smoking is hard and may require several attempts, as people who stop smoking often start again because of weight gain, stress and withdrawal symptoms. Nicotine withdrawal symptoms may include feeling irritable, angry, or anxious, craving tobacco products and feeling hungrier than usual [4]. 
Therefore, this study was designed to determine the prevalence of smoking status in housing area at Bandar Baru Salak Tinggi, Sepang Selangor and identify challenges to quit smoking among smokers in the community.

\section{RESEARCH METHOD}

A cross-sectional study was conducted in a housing area at Bandar Baru Salak Tinggi, Sepang, Selangor, Malaysia. The area has been chosen as the community to be studied due to the fact that it has multiracial residents and is accessible. Stratified random sampling was used to classify the houses into two groups, single-storey and double-storey. Systematic random sampling was then used to pick the houses in each stratum accordingly and simple random sampling using drawing lots to choose the respondents in the house. Only Malaysians aged 15 years and above, who had been the residents for at least one month were chosen as respondents. Residents who smoke less than one month, with mental impairment and unable to speak were excluded in this survey.

Data was collected through face to face assisted questionnaire interview to identify challenges to quit smoking. The questionnaires has been adopted and adapted from the Challenges Stop Smoking (CSS) 21 scale (Cronbach's $\alpha$ : 0.86) [5]. The questions for challenges to quit smoking have been divided into three barriers, namely addiction, internal and external. Each barrier has 5 questions. A two-point scale (yes or no) has been used for recording responses.

Each question has been analysed using scores. Every 'Yes' answer got 1 score and every 'No' answer got score 0 . Scores for items in each subscale have been added up to create two composite challenges scores. Data was analyzed using Statistical Package Social Sciences (SPSS) version 20. The mean of each factor was calculated by dividing the factor score with the grand total through the SPSS. The factor with a higher calculated mean is identified as more challenging.

\section{RESULTS AND ANALYSIS}

A total of 228 participants participated in this study, which gave a response rate of $100 \%$. Majority of the respondents were female $(58.3 \%)$, Malay $(67.5 \%)$ with age ranged $30-39(26.8 \%)$. Most of them were working in private sectors $(27.2 \%)$, had secondary education $(58.3 \%)$ and still married (77.6\%). Among the respondents, $15.8 \%$ were smokers (Table 1 ).

Table 1. Prevalence of Smoking among Respondents

\begin{tabular}{ccc}
\hline Smoking status & No. & $\%$ \\
\hline Smoker & 36 & 15.8 \\
Non-smoker & 192 & 84.2 \\
Total & 228 & 100 \\
\hline
\end{tabular}

Table 2 shows that $100 \%$ of smokers were male respondents. There were higher prevalence of smoking among 20-29 years old (25.6\%), Malays (16.7\%), those with secondary formal education (16.2\%), single (17.9\%), respondents who earned an income of more than RM3000 a month (17.4\%) and pensioner $(28.6 \%)$. However, only gender and occupation showed significant association $(\mathrm{p}<0.05)$ with smoking status.

Table 3 describes that seeing things/people which reminded the respondents of smoking $(0.58 \pm$ $0.50)$ was the most challenging factor under addiction barrier, followed by feeling lost without smoking $(0.53$ $\pm 0.51)$ and withdrawal symptoms $(0.47 \pm 0.51)$. In the list of internal barrier, the fear of failing to quit $(0.53$ $\pm 0.51)$, belief that medicines to stop smoking does not work $(0.31 \pm 0.47)$ and fear of gaining weight $(0.28 \pm$ $0.45)$ were the more challenging factors. Whereas easy availability of cigarettes $(0.86 \pm 0.35)$, cost of stop smoking medicine $(0.33 \pm 0.48)$ and difficulty in finding someone to help them stop smoking $(0.28 \pm 0.45)$ were the challenges under the external barrier.

Generally, easy availability of cigarette was the most challenging factor while fear that stop smoking may interrupt social relationships and lack of encouragement in refusal to quit smoking were reported to be the least challenging factors for smokers to quit smoking. 
Table 2. Smoking Status among Respondents by Socio-demographic

\begin{tabular}{|c|c|c|c|c|}
\hline Sociodemographic factors & $\begin{array}{c}\text { Smoker } \\
\mathrm{n}(\%)\end{array}$ & $\begin{array}{c}\text { Non-smoker } \\
\mathrm{n}(\%)\end{array}$ & $\begin{array}{l}\text { Total } \\
\mathrm{n}(\%)\end{array}$ & $\begin{array}{c}\mathrm{P} \\
\text { value }\end{array}$ \\
\hline \multicolumn{5}{|l|}{ Age } \\
\hline$\leq 19$ years old & $1(9.1)$ & $10(90.9)$ & $11(100)$ & \multirow{6}{*}{0.374} \\
\hline $20-29$ years old & $10(25.6)$ & $29(74.4)$ & $39(100)$ & \\
\hline 30 - 39 years old & $8(13.1)$ & $53(86.9)$ & $61(100)$ & \\
\hline 40 - 49 years old & $8(22.2)$ & $28(77.8)$ & $36(100)$ & \\
\hline 50 - 59 years old & $4(10.8)$ & $33(89.2)$ & $37(100)$ & \\
\hline$\geq 60$ years old & $6(13.6)$ & $38(86.4)$ & $44(100)$ & \\
\hline \multicolumn{5}{|l|}{ Gender } \\
\hline Male & $36(37.9)$ & $59(62.1)$ & $95(100)$ & \multirow[t]{2}{*}{0.000} \\
\hline Female & $0(0)$ & $133(100)$ & $133(100)$ & \\
\hline \multicolumn{5}{|l|}{ Race } \\
\hline Malay & $28(18.2)$ & $126(81.8)$ & $154(100)$ & \multirow{4}{*}{0.153} \\
\hline Chinese & $0(0)$ & $2(100)$ & $2(100)$ & \\
\hline Indian & $7(10.1)$ & $62(89.9)$ & $69(100)$ & \\
\hline Bajau & $1(33.3)$ & $2(66.7)$ & $3(100)$ & \\
\hline \multicolumn{5}{|l|}{ Academic Status } \\
\hline No formal education & $0(0)$ & $6(100)$ & $6(100)$ & \multirow{4}{*}{0.593} \\
\hline Primary education & $2(6.5)$ & $29(93.5)$ & $31(100)$ & \\
\hline Secondary education & $28(21.1)$ & $105(78.9)$ & $133(100)$ & \\
\hline Tertiary education & $7(12.1)$ & $51(87.9)$ & $57(100)$ & \\
\hline \multicolumn{5}{|l|}{ Marital Status } \\
\hline Single & 7 (17.9) & $32(82.1)$ & $39(100)$ & \multirow{3}{*}{0.727} \\
\hline Married & $28(15.8)$ & $149(84.2)$ & $177(100)$ & \\
\hline Divorced & $1(8.3)$ & $11(91.7)$ & $12(100)$ & \\
\hline \multicolumn{5}{|l|}{ Monthly income } \\
\hline$<$ RM2000 & $15(15.3)^{-}$ & $83(84.7)$ & $98(100)$ & \multirow{3}{*}{0.822} \\
\hline RM 2000 - RM 2999 & $5(13.2)$ & $33(86.8)$ & $38(100)$ & \\
\hline$>$ RM 3000 & $16(17.4)$ & $76(82.6)$ & $92(100)$ & \\
\hline \multicolumn{5}{|l|}{ Occupation } \\
\hline Government & $7(24.1)$ & $22(75.9)$ & $29(100)$ & \multirow{7}{*}{0.000} \\
\hline Private & $17(27.4)$ & $45(72.6)$ & $62(100)$ & \\
\hline Self-employed & $4(17.4)$ & $19(83.6)$ & $23(100)$ & \\
\hline Students & $1(6.7)$ & $14(93.3)$ & $15(100)$ & \\
\hline Not working & $3(8.6)$ & $32(91.4)$ & $35(100)$ & \\
\hline Housewife & $0(0)$ & $50(100)$ & $50(100)$ & \\
\hline Pensioner & $4(28.6)$ & $10(71.4)$ & $14(100)$ & \\
\hline
\end{tabular}

Table 3. Refusal Factors to Quit Smoking

\begin{tabular}{lc}
\hline \multicolumn{1}{c}{ Factors } & Mean \pm S.D \\
\hline Addiction barrier & \\
Seeing things/people which reminded me of smoking & $0.58 \pm 0.50$ \\
Feeling lost without smoking & $0.53 \pm 0.51$ \\
Withdrawal symptoms & $0.47 \pm 0.51$ \\
Something stressful happened & $0.42 \pm 0.50$ \\
Having strong emotions or feelings & $0.22 \pm 0.42$ \\
Internal barrier & \\
Fear of failing to stop smoking & $0.53 \pm 0.51$ \\
Belief that medicines to stop smoking do not work & $0.31 \pm 0.47$ \\
Fear of weight gain & $0.28 \pm 0.45$ \\
Fear of side effects of stop smoking medicines & $0.25 \pm 0.44$ \\
Fear that stopping smoking may interrupt social relationships & $0.11 \pm 0.32$ \\
External barrier & \\
Easy availability of cigarettes & $0.86 \pm 0.35$ \\
The cost of stop-smoking medicines & $0.33 \pm 0.48$ \\
Difficulty in finding someone to help me to stop smoking. & $0.28 \pm 0.45$ \\
Lack of encouragement from family or friends to stop smoking & $0.17 \pm 0.38$ \\
Lack of encouragement from health professionals to stop smoking & $0.11 \pm 0.32$ \\
\hline
\end{tabular}

\section{DISCUSSION}

Based on our study, $15.8 \%$ of respondents were smokers, lower than GATS in which $23.1 \%$ of population is smokers [6]. This might be due to the lower number of male respondents compared to female in this study and only male respondents who smoke. However, the prevalence of smoking among male was 37.9\%, consistent with the National Health and Morbidity Survey in 2015 that shows 38.8\% of smokers are men [2]. Smoking is considered to be socially acceptable among men compared with women in the majority of South African communities [7] and gender was significantly associated with smoking in our study, thus 
accounting for the higher prevalence of smoking recorded among men. In addition, smoking makes young people look more mature, makes young men look more attractive and helps to control body weight [8]. These might be true as $28 \%$ of our smokers afraid to quit smoking as fear of weight gain.

A cross-sectional study done by Huot, et al. indicates that body weight, or body mass index (BMI; in $\mathrm{kg} / \mathrm{m}^{2}$ ), is lower in cigarette smokers than in non-smokers [9]. Numerous studies have shown that persons who quit smoking are likely to gain weight, as reviewed by Ward, et al. [10] and Filozof, et al. [11]. The prospect of gaining weight can discourage smokers from quitting. In addition, weight gain increases the risk of relapse, particularly among normal-weight or underweight women who report chronic dieting [12], but also among men [13].

Relapse due to nicotine dependency is being reported as a reason for not quitting smoking [14], which is consistent with our finding where withdrawal symptoms was one of the challenges. Nicotine is highly addictive and is predicted that one in two long-term smokers will die from tobacco addiction [15]. In the short term, nicotine increases energy expenditure and could reduce appetite, which may explain why smokers tend to have lower body weight than do non-smokers and why smoking cessation is frequently followed by weight gain [16]. One of the ways to combat this is by using Nicotine Replacement Therapies (NRTs) such as gum and transdermal patch, which are able to increase the rate of quitting by 50 to $70 \%$, by reducing the withdrawal symptoms [17].

Majority of the smokers are at the age of 21-30 years of age (59.3\%) [18], and found to be the largest and significant smoking group [19]. These would represent the successful influence and advertisement by tobacco companies to the youngsters [8], and the lack of perception of harmful effects of tobacco amongst Malaysians, higher affordability, easy availability and accessibility to tobacco products in Malaysia [19]. Easy availability of cigarettes was the most challenging factor to quit smoking in our study and this may suggest poor law enforcement and compliance or easy availability of cheap, smuggled cigarettes [20]. Hum, et al. also reported that a $10.0 \%$ increase in price would result in a $3.8 \%$ reduction in cigarette consumption over the long-run if annual tobacco tax increases were made, whereas Firend in his study showed that $55.17 \%$ of smokers under the age of 18 showed willingness to reduce or quit smoking if prices increase [21]. Therefore, the government should raise cigarette prices to reduce cigarette use, as recommended in the WHO MPOWER strategy for tobacco control [22]. Further actions, such as, establishing and strengthening regulations should also be taken to prevent wholesalers and retailers from selling tobacco products below a fixed price [23].

A study on the prevalence of smoking and its associated factors among university staffs, showed that the majority of smokers are married $(74.1 \%)$ followed by single $(23.9 \%)$, divorced $(1 \%)$ and widowed (1\%) [24]. However, it is inconsistent with our finding and a study done in Sweden, which the prevalence of smoking among divorced man (49.3\%) is higher compared to unmarried man $(47.2 \%)$ and married man (38.4\%) [25]. Marriage often comes with responsibilities and married participants are more likely to be restricted in their ability to purchase cigarettes [7]. Positive influence of social support sustained on cessation of smoking and living under a partial or total home smoking ban are positively associated with successful cessation [26],[27]. The absence of other smokers in the household is also a significant predictor [28]. Among successful quitters, $68 \%$ are married or living with a partner and those successful quitters are more likely to have rules against smoking in their homes. People who have a smoke-free home or workplace are 10 times as likely to be successful quitters as those who live in a home or workplace where smoking took place [29].

Both workplace and household smoking restrictions were associated with higher rates of cessation attempts, lower rates of relapse in smokers who attempt to quit [27]. Smoke-free workplaces not only protect non-smokers from the dangers of passive smoking, they also encourage smokers to quit or to reduce consumption, where totally smoke-free workplaces are associated with reductions in prevalence of smoking of 3.8\% [30]. Forty six percent of the smokers in a study done by Raúl H. Sansores, M. en C, et al. indicate that they smoke at work. The administrative staff and researchers reported a higher significant number of subjects who smoke in their areas of work and this might be the privacy that the administrators and researchers have to smoke in their offices [31]. Thus, higher prevalence of smoking among the private workers in our study might be due to the operation in a private work environment, which makes it less difficult to enforce anti-smoking regulations [7].

Several studies show that laws enforcement plays an important role, where a 1995 Finnish law that prohibited smoking in public areas in workplaces (with the option of creating separately ventilated smoking rooms) was associated with a $4.5 \%$ drop in prevalence of smoking and three fewer cigarettes smoked per day among continuing smokers [32] and strong local ordinances in California in 1990-1 are associated with an absolute quit rate (over the previous six months) $7.6 \%$ higher than in areas with no workplace laws [33]. Malaysia has put an effort to control tobacco use in public places by introducing the Control of Tobacco Product Regulation under the Food Act 1983 [34]. The regulation which was issued in 2004

IJPHS Vol. 7, No. 1, March 2018:65-71 
aimed to regulate, among other things, smoke-free environments; tobacco advertising, promotion and sponsorship; as well as tobacco packaging and labelling. Amendments of Regulation 11 were made in 2008 and 2010 and at present there are up to 21 public places listed as smoke-prohibited places. However, compliance level to smoke-free legislation implementation is unable to show its positive effects in protecting the health of the public [35] as cigarettes are easily available.

David and Edward reported that the first reason that one person's smoking, or eating or exercise, might positively influence a neighbor's choices as it is more pleasant to do something together than alone. Smoking and exercise may be somewhat less social activities, but many people like to exercise or smoke with friends around. Conversely, smoking around a non-smoker can be much less pleasant because of the discomfort caused by second-hand smoke to a non-smoker. Workplace smoking bans causes $40 \%$ more likely smokers to smoke alone [36]. Thus accounting for the higher prevalence of fear to quit smoking among our smokers as this may interrupt their social relationships.

Over the years, we have used the risks and dangers of smoking towards health as interventions to motivate smokers to quit smoking [20]. Majority of smokers (70\%) knew of the risks and dangers of smoking and have also came across ads that reminded them of the dangers of smoking [2]. However, only $15 \%$ of smokers stop smoking despite $80 \%$ of smokers acknowledged smoking as a cause of lung cancer and this may reflect that knowledge on the disadvantages of smoking to not play a role in the decision to quit smoking in most smokers [37].

More than $50 \%$ of our smokers claimed that they refused to quit smoking due to fear of failure. Studies have shown, over $60 \%$ of smokers claimed that it would be hard to maintain abstinence if they quit smoking [38] and of the many who had tried to quit in the past, all had done so on their own initiative, and several described a lack of support or active discouragement by practitioners to address smoking, which contribute to their failure [39]. These were consistent with our findings where lack of encouragement from health professionals $(11 \%)$ and family or friends (17\%) to stop smoking as the challenges.

Social support identifies persons who will be encouraging about cessation, finds "buddies" who are also either trying to quit or have done so, etc. It increases quit rates by a factor of 1.3 to 1.5 [40]. Whereas, behavioral therapy focuses on building skills to resist relapse such as developing incompatible behaviors (e.g., exercise), coping thoughts, refusal skills, etc. [41]. This therapy increases quit rates by a factor of 1.5 to 2.1 [42],[43]. Buczkowski, et al. in their research has identified that the two of the most important factors that affect the efficacy of quitting smoking are motivation and the ability to cope with situations causing relapse, showing that high motivation and perseverance is needed to quit smoking [44]. They also suggest that video presentations are the strongest motivator to quit smoking when health is matters and are successful for smokers with a low readiness to quit smoking [45]. However, whatever the methods are being used maintain the smoking cessation; the most important aspect is to make multiple attempts [46].

\section{CONCLUSION}

Easy availability of cigarettes, fear of failing to quit smoking as seeing things will reminded smokers of smoking, may interrupt social relationships and lack of encouragement were challenges to quit smoking among the smokers in Bandar Baru Salak Tinggi, Sepang, Selangor. Therefore, other than increase the price of cigarettes, government should strengthen the enforcement on regulations advertisement and display of cigarettes. There should be more health promotion on disadvantages of smoking to public especially youngsters and more activities on motivation among smokers and their families, which may be organized by government or non-government organizations. Health premises should welcome more references or walk in potential smokers who wish to quit smoking and plan an interesting customize program for them. The most important aspect is the promoting smoking cessation program might benefit by involving family or other household members to encourage smoke-free homes.

\section{ACKNOWLEDGEMENTS}

The authors would like to acknowledge the Cyberjaya University College of Medical Sciences (CUCMS), for for the financial help and giving the permission to carry out this study. We are also acknowledging the residents of Taman Cempaka, Bandar Baru Salak Tinggi, Sepang, Malaysia as the respondents. Also thank you to Group 4, Class of 2015 undergraduate medical students in the Discipline of Community Medicine, CUCMS as the data collectors. 


\section{REFERENCES}

[1] H. Hussain, et al., "Smoking in children: Putrajaya," Malaysian Journal of Public Health Medicine, vol/issue: 8(2), pp. $11-12,2008$.

[2] NHMS (National Health and Morbidity Survey), "Report on smoking status among Malaysian Adults, Kuala Lumpur, Malaysia," Institute for Public Health, Ministry of Health, Malaysia, 2015.

[3] WHO, "Facts Sheets: Tobacco," 2017. www.who.int/mediacentre/factsheets/fs339/en/.

[4] CDC (Centers for Disease Control and Prevention), "Fact Sheet: Quitting Smoking," 2017. https://www.cdc.gov/tobacco/data_statistics/fact_sheets/cessation/quitting/index.htm.

[5] T. J. Dennis, et al., "Development and validation of a 21-item challenges to stopping smoking (CSS-21) scale," BMJ Open, vol/issue: 6(3), pp. 8, 2016.

[6] GATS (Global Adult Tobacco Survey), "Report of the Global Adult Tobacco Survey Malaysia, 2011," Institute for Public Health, Ministry of Health Malaysia, pp. 14-15, 2011.

[7] E. O. Owolabi, et al., "Prevalence and factors associated with tobacco use among adults attending selected healthcare facilities in Buffalo City Metropolitan Municipality, South Africa," South African Family Practice, vol/issue: 59(6), pp. 201-201, 2017.

[8] C. M. Parkinson, et al., "Smoking Beliefs and Behavior among Youth in Malaysia and Thailand," American Journal of Health Behaviour, vol/issue: 33(4), pp. 366-375, 2009.

[9] I. Huot, et al., "Quebec Heart Health Demonstration Project Research Group. Factors associated with overweight and obesity in Quebec adults," Int J Obes Relat Metab Disord., vol/issue: 28(6), pp. 766-74, 2004.

[10] K. D. Ward, et al., "Cessation of smoking and body weight," in Björntop P, "International textbook of obesity," Chichester, United Kingdom, Wiley \& Sons Ltd, pp. 323-36, 2001.

[11] C. Filozof, et al., "Smoking cessation and weight gain," Obes Rev., vol/issue: 5(2), pp. 95-103, 2004.

[12] A. W. Meyers, et al., "Are weight concerns predictive of smoking cessation? A prospective analysis," J Consult Clin Psychol, vol/issue: 65(3), pp. 448-52, 1997.

[13] M. M. Clark, et al., "Weight concerns among male smokers," Addict Behav., vol/issue: 29(8), pp. 1637-41, 2004.

[14] A. C. Villanti, et al., "Reasons to quit and barriers to quitting smoking in US young adults," Family Practice, vol/issue: 33(2), pp. 133-139, 2016.

[15] WHO, "Gender, Women, and the Tobacco Epidemic," Geneva, Switzerland, WHO Press, 2010. http://apps.who.int/iris/bitstream/10665/44342/1/9789241599511_eng.pdf

[16] C. Arnaud, et al., "Consequences of smoking for body weight, body fat distribution, and insulin resistance," Am J Clin Nutr. Vol/issue: 87(4), pp. 801-809, 2008.

[17] L. F. Stead, et al., "Nicotine replacement therapy for smoking cessation," Cochrane Database of Systematic Review, vol. 11, 2012. https://www.ncbi.nlm.nih.gov/pubmed/23152200.

[18] H. K. Lim, et al., "Epidemiology of smoking among Malaysian adult males: Prevalence and associated factors," BMC Public Health, vol/issue: 13(8), pp. 4, 2013.

[19] M. M. Rahman, et al., "Factors associated with tobacco use among the adult population in sarawak, Malaysia," Epidemiology Biostatistics and Public Health, vol/issue: 12(1), pp. 6-7, 2015.

[20] W. L. Hum, et al., "A Review of Smoking Research in Malaysia," Medical Journal Malaysia, vol/issue: 71(1), pp. 1-13, 2016.

[21] A. R. Firend, "Government Pricing Policy and Behavioral Consumption of Tobacco," International Journal of Innovative Science, Engineering \& Technology, vol/issue: 2(10), pp. 1-5, 2015.

[22] WHO, "MPOWER: A policy package to reverse the tobacco epidemic," Geneva, Switzerland, WHO Press, 2008.

[23] L. Henriksen, "Comprehensive tobacco marketing restrictions: promotion, packaging, price and place," Tobacco Control, vol. 21, pp. 147-153, 2012.

[24] A. A. Fasoro, et al., "Prevalence of Smoking and Its Associated Factors among University Staff," Malaysian Journal of Medicine and Health Science, vol/issue: 9(2), pp. 45-51, 2013.

[25] M. Lindström, "Social capital, economic conditions, marital status and daily smoking: A population-based study," Public health, vol/issue: 124(2), 2010.

[26] C. A. Derby, et al., "Characteristics of smokers who attempt to quit and of those who recently succeeded," $A M J$ PREV MED, vol/issue: 10(6), pp. 327-34, 1994.

[27] A. J. Farkas, et al., "The effects of household and workplace smoking restrictions on quitting behaviours," Tob Control, vol. 8, pp. 261-265, 1999.

[28] N. Hymowitz, et al., "Predictors of smoking cessation in a cohort of adult smokers followed for five years," Tob Control, vol/issue: 6(2), pp. S57-S62, 1997.

[29] Chung W. L. and Jennifer K., "Factors Associated with Successful Smoking Cessation in the United States, 2000," American Journal of Public Health, vol/issue: 97(8), 2000.

[30] M. F. Caroline and A. G. Stanton, "Effect of smoke-free workplaces on smoking behaviour: systematic review," $B M J$, vol/issue: 325(7357), pp. 188, 2002.

[31] R. H. Sansores, et al., "Prevalence of cigarette smoking among employees of the Mexican National Institutes of Health," Salud pública Méx., vol/issue: 41(5), 1999.

[32] A. Heloma, et al., "The short-term impact of national smoke-free workplace legislation on passive smoking and tobacco use," Am J Pub Health, vol. 91, pp. 1416-1418, 2001.

[33] J. M. Moskowitz, et al., "The impact of workplace smoking ordinances in California on smoking cessation," Am J Public Health, vol. 90, pp. 757-761, 2000. 
[34] Malaysia Food Act, "Control of Tobacco Product Regulations 2004," Part IV: Prohibition on Smoking; International Law Book Services, pp. 335-348, 2004.

[35] Z. A. Najihah, et al., "Smoke-Free Legislation in Malaysia: A comprehensive review," Asia Pacific Environmental and Occupational Health Journal, vol/issue: 2(2), pp. 58 - 66, 2016.

[36] M. C. David and L. G. Edward, "Social Interactions and Smoking," NBER Working Paper No. 13477, 2007.

[37] H. G. Cheng, et al., "Relationship between knowledge about the harms of smoking and smoking status," Global Adult Tobacco China Survey, vol. 24, pp. 54-61, 2010.

[38] R. M. Kathryn, et al., "Perceived barriers to smoking cessation among adults with substance use disorders," Journal of Substance Abuse Treatment, vol. 74, pp. 48-53, 2016.

[39] G. Laura and R. Elena, "Tobacco smoking, associated risk behaviours, and experience with quitting: a qualitative study with homeless smokers addicted to drugs and alcohol," BMC Public Health, vol. 13, pp. 951, 2013.

[40] M. C. Fiore, et al., "Treating Tobacco Use and Dependence Clinical Practice Guideline," Rockville, MD: Public Health Service, 2000.

[41] J. R. Hughes, "Behavioral support programs for smoking cessation,” Mod Med., vol. 62, pp. 22-7, 1994.

[42] T. Lancaster and L. F. Stead, "Individual Behavioural Counselling for Smoking Cessation," The Cochrane Library, vol/issue: 18(2), 2005.

[43] L. F. Stead and T. Lancaster, "Group Behaviour Therapy Programmes for Smoking Cessation," The Cochrane Library, vol/issue: 18(2), 2005.

[44] K. Buczkowski, et al., "Motivations toward smoking cessation, reasons for relapse, and modes of quitting: results from a qualitative study among former and current smokers," Patient Prefer Adherence, vol. 8, pp. 1353-1363, 2014.

[45] J. Brown, et al., "An Online Documentary Film to Motivate Quit Attempts Among Smokers in the General Population (4Weeks2Freedom): A Randomized Controlled Trial," Nicotine \& Tobacco Research, vol/issue: 18(5), pp. 1093-1100, 2016.

[46] J. R. Hughes, "Motivating and Helping Smokers to Stop Smoking," J Gen Intern Med., vol/issue: 8(12), pp. 1053$1057,2003$. 